Sharif University of Technology
Scientia Iranica
SCIENTIA
IRAN I CA

\title{
Conditioning of vitrified and resin bond CBN grinding wheels using a picosecond laser
}

\author{
A. Zahedia,*, B. Azarhoushang ${ }^{\mathrm{a}}$ and J. Akbari ${ }^{\mathrm{b}}$ \\ a. Institute for Precision Machining (KSF), Furtwangen University, 78054 Schwenningen, Baden-Wuttemberg, Germany. \\ b. Center of Excellence in Design, Robotics and Automation, School of Mechanical Engineering, Sharif University of Technology, \\ Tehran, Iran.
}

Received 15 May 2014; received in revised form 25 April 2016; accepted 26 September 2016

\section{KEYWORDS}

Picosecond Yb:YAG

laser;

Vitrified bond;

Resin bond;

CBN grinding wheel;

Laser conditioning.

\begin{abstract}
Laser ablation is a novel non-mechanical wheel preparation method for optimizing the treatment costs of superabrasive tools. In this study, the thermal effects of picosecond laser radiation on vitrified and resin bond CBN superabrasive grinding wheel surfaces were analytically and experimentally investigated. The analytical approach was intended to find threshold process parameters for selective ablation of cutting grains and bond material. A picosecond Yb:YAG laser device was integrated with a cylindrical grinding machine, which facilitated the treatment of grinding wheel as it was mounted on the grinding spindle. It is shown that the extent of material ablation is defined by the maximum surface temperature induced by the laser radiation, which is in turn defined by the laser pulse energy. It is also suggested that the depth of laser thermal effects is governed by the relative speed of the laser scanner with respect to the wheel surface.
\end{abstract}

(C) 2017 Sharif University of Technology. All rights reserved.

\section{Introduction}

The development of superabrasive grinding tools has revolutionized the grinding process as a crucial part of manufacturing technology. Nevertheless, the conventional conditioning of superabrasive tools is challenging owing to their high hardness and, accordingly, high dressing tool wear and cost, long process time, and pollution, which have hindered the overall acceptance of the superabrasive tools in industry $[1,2]$. Nonmechanical wheel preparation methods such as ELID (electrolytic in process dressing), electro-discharge dressing, and laser dressing are novel approaches to

\footnotetext{
*. Corresponding author. Tel.: +49 7720 9979811

Fax: +49 7rog 955779

E-mail addresses: ali.zahedi@hs-furtwangen.de (A. Zahedi)

aza@hs-furtwangen.de (B. Azarhoushang)

akbari@sharif.edu (J.Akbari)
}

doi: $10.24200 /$ sci. 2017.4307 reducing the treatment costs of superabrasive tools. Despite the high initial investment, these techniques are economical in long time due to their positive features like no conditioning tool wear, high speed and controllability, flexibility, environmental friendliness, and limited surface damage.

The first attempts at studying the effects of laser on grinding wheel surface were made in late 1980s, where the laser dressing of conventional alumina wheels was investigated [3,4]. The radiation of the laser beam on the wheel surface can cause the local melting of the bond material and/or the cutting grains. The laser radiation can also help the conventional mechanical dressing methods by the local softening of the wheel material ahead of the dressing tool [5]. In addition to high repeatability, laser dressing provides favorable grinding forces, wheel wear, and ground surface conditions in comparison with the mechanical contact methods $[3,4,6]$. The benefits are more pronounced when applying the method to 
superabrasive wheels, which are associated with higher costs and more conditioning challenges [7-10]. It is also demonstrated that, owing to higher controllability and smaller heat-affected zone, the application of pulsed lasers is more promising than that of Continuous Wave (CW) lasers [11]. While retaining the same grinding performance as that in grinding with conventionally dressed wheels, laser dressed metal bond diamond wheels are subject to less grain damage and less surface crack propagation [12]. Thermal analysis of the cooling process in laser assisted dressing of alumina wheels suggests the generation of preferable multifaceted grains, which favors the cutting action [13,14]. Touch dressing of electroplated diamond wheels is also made possible using an ultra-short pulsed picosecond laser $[15,16]$. The application of ultra-short pulsed lasers for the conditioning of superabrasive tools has also been reported in literature $[17,18]$.

Topographical analysis of the grinding process has shown that only a very small portion of the static cutting edges are involved in the cutting action (dynamic cutting edges) while the rest are engaged in the rubbing and ploughing regimes, doing no material removal [19]. The ratio of the dynamic to the static cutting edges is reported to be in the range of $2 \%$ to $12 \%$ [20]. The ratio could be increased by reducing the number of momentarily engaging cutting grains while increasing the average chip thickness. A wellknown method to perform this task is to diminish the number of static cutting edges via segmentation of the grinding wheel [21]. Regarding the high controllability, repeatability, and precision of the grinding wheel laser treatment, the structuring process can also be conducted. Therefore, a wide range of applications from conventional conditioning (dressing and truing) to structuring can be performed with the same concept over a wide variety of grinding wheel types.

Considering the ability of the laser treatment to replace the conventional grinding wheel preparation methods, and to generate arbitrary structures on the grinding wheel surface, a methodology is proposed to perform the whole range of processes in terms of laser conditioning. Therefore, the truing, dressing, and structuring of the grinding wheel can be flexibly done with the same equipment when comprehensive understanding of the underlying process is achieved. As the laser treatment is a thermal process, thermal behavior of the laser-radiated surface is investigated. Owing to different thermal properties of the grinding wheel components, the selective treatment of cutting grains or the bond material would be possible. Accordingly, the threshold laser power values are found for arbitrary treatment of the grinding wheel components. The effect of laser scanning speed on the conditioning process is also investigated. Owing to its ultra-short pulse duration (<10 ps), a Yb:YAG picosecond laser device is chosen and integrated with a cylindrical grinding machine. This integration facilitates the accomplishment of in-process laser treatment. The processing time would also be shortened by eliminating the grinding wheel handling and assembly time. Accordingly, laser ablation tests are conducted to assess the efficiency of the method in practice and verify the theoretical background.

\section{Laser conditioning equipment}

A Yb:YAG TruMicro5050 picosecond laser device is used in the current research for thermal conditioning of CBN grinding wheels. The exit beam of the laser with $5 \mathrm{~mm}$ diameter cannot be readily radiated to the surface. In addition, to be transferred to the point of interest, the beam should be focused with an optical scanner. The principle of laser structuring is schematically presented in Figure 1, where the beam is guided through some mirrors from the laser head to the laser scanner.

The laser scanner is mounted on a vertical stage, which can position the scanner in the vertical direction. The other required motion components (two horizontal and one rotational) are provided by the grinding machine spindle. The motion components are presented by arrows in Figure 1. Vitrified and resin bond CBN grinding wheels with $64 \mu \mathrm{m}$ average grain size were chosen for laser treatment experiments. The laser scanner, the focusing lens, and a grinding wheel installed in the grinding machine are presented in Figure 2.

Depending on the optical lens in use, the distance between the laser scanner and the grinding wheel surface is adjusted according to the focal length of the lens. Performing the laser radiation in the focal point provides the highest energy concentration and the finest zone of treatment for selective treatment of the grinding wheel components.

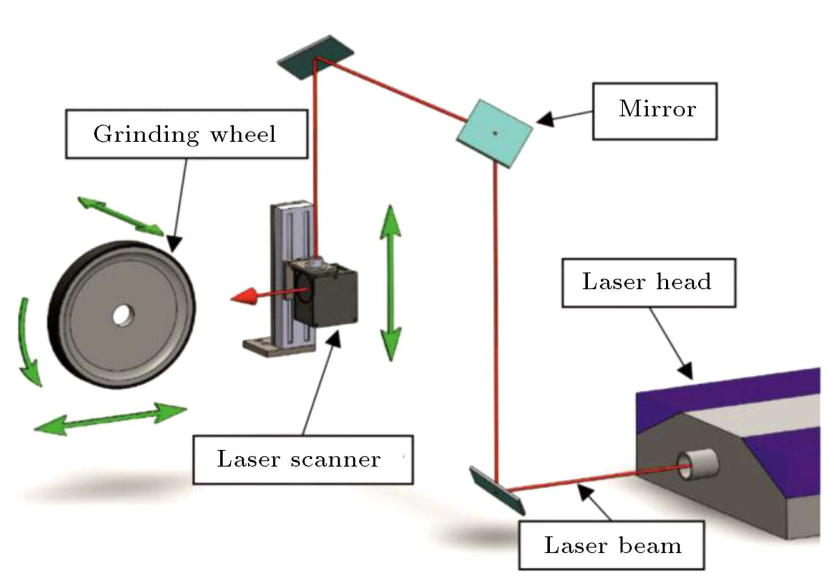

Figure 1. Grinding wheel conditioning concept. 


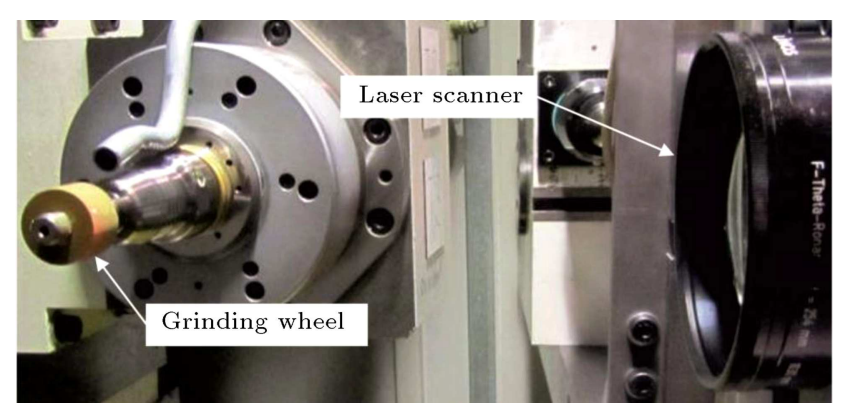

Figure 2. Laser scanner and grinding spindle combination.

\section{Thermal analysis of laser conditioning}

Laser conditioning is a thermal process in which a focused high-energy laser beam melts or evaporates every solid material at its focal point. The overall laser treatment can be resolved into the action of individual pulses. Owing to the ultra-short duration of a picosecond laser pulse, the convective heat loss from the grinding wheel surface is negligible. Therefore, only the heat conduction within the grinding wheel body is considered in the present analysis.

The thermal conduction in a solid medium is governed by the heat conduction equation (known as Fourier model), which has the following general form for isotropic materials [22]:

$$
\rho c \frac{\partial T}{\partial t}=\nabla \cdot(k \nabla T)+q . .^{\prime \prime}
$$

The equation describes the temperature, $T$, with respect to time, $t$, and spatial coordinates, where $\rho$, $c$, and $k$ are the density, specific heat capacity, and thermal conductivity of the material, respectively. The last term, $q^{\prime \prime}$, is the internal heat generation per unit volume of the material. Considering the laser beam as a point source of thermal energy, which is small in comparison with grinding wheel size, the grinding wheel would be assumed as a semi-infinite half space. The laser pulse would raise the temperature of a point on the surface of the wheel to a maximum value in a short time ( $<10 \mathrm{ps}$ ) after which the heat would be dissipated inside the medium. The thermal properties of the wheel components are presented in Table 1 as they would be addressed later.

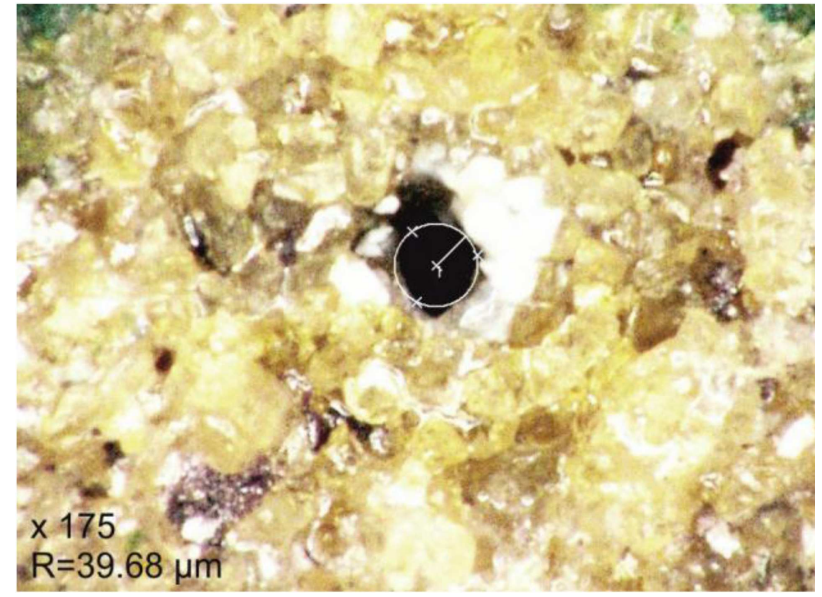

Figure 3. Laser radiated zone generated by a steady beam at the focal point.

Before going further in simplifying the heat conduction equation, the irradiation of laser pulse on the grinding wheel surface would be considered. The laser device is adjusted at $100 \%$ power corresponding to 125 $\mu \mathrm{J}$ pulse energy (to get the highest effect) and $400 \mathrm{kHz}$ repetition rate, and the beam is released at a point on the wheel surface. The picture of the generated zone is shown in Figure 3, where its radius is measured to be about $40 \mu \mathrm{m}$.

The laser pulse incidence on the surface can be considered as a thermal disturbance in a short pulse width, $t_{0}$, which takes the local surface temperature up to $T_{\max }$. The distance a change of temperature would propagate during a pulse duration can be defined by the thermal diffusion length, which is expressed as [25]:

$$
2 L=2 \sqrt{\alpha t_{0}},
$$

where $\alpha$ is the thermal diffusivity of the material and is equal to $k / \rho \mathrm{c}$. As the pulse width of the laser is less than $10 \mathrm{ps}$, the thermal diffusivity length values for a CBN grain, vitrified bond, and resin bond material would be $0.17 \mu \mathrm{m}, 0.02 \mu \mathrm{m}$, and $0.0025 \mu \mathrm{m}$, respectively, which are much smaller than the average grain size and the beam diameter in both cases. Therefore, the heat transfer during a single pulse can be assumed to take place just in one material (either the grain or the bond material). Considering the grain and bond

Table 1. Thermal properties of CBN grains and the vitrified and resin bond material [1,23,24].

\begin{tabular}{cccc}
\hline Parameter & CBN & $\begin{array}{c}\text { Vitrified } \\
\text { bond }\end{array}$ & $\begin{array}{c}\text { Resin } \\
\text { bond }\end{array}$ \\
\hline Density $\left(\mathrm{kg} / \mathrm{m}^{3}\right)$ & 3480 & 3625 & 1100 \\
Specific heat $(\mathrm{J} / \mathrm{kgK})$ & 506 & 840 & 1200 \\
Thermal conductivity $(\mathrm{W} / \mathrm{mK})$ & 1300 & 30 & 0.21 \\
Thermal diffusivity $\left(\mathrm{m}^{2} / \mathrm{s}\right)$ & $7.4 \times 10^{-4}$ & $9.8 \times 10^{-6}$ & $1.59 \times 10^{-7}$ \\
Melting temperature $\left({ }^{\circ} \mathrm{C}\right)$ & 3227 & $1500-2500$ & $302-497$ \\
\hline
\end{tabular}


material as homogenous bodies, and eliminating the internal heat generation term, the heat conduction equation can be simplified as:

$$
\frac{\partial T}{\partial t}=\alpha \nabla^{2} T
$$

The solution to Eq. (3) for a cooling semi-infinite body on the points along the axis exactly under the radiation zone can be expressed as [26]:

$$
T(z, t)=T_{\max }+\left(T_{i}-T_{\max }\right) \operatorname{erfc}\left(\frac{z}{2 \sqrt{\alpha t}}\right)
$$

where $T_{i}$ is the initial body temperature (before the radiation of laser beam), $T_{\max }$ is the surface temperature corresponding to the thermal disturbance, and $z$ is the position along the axis facing inside the body from the surface. $\operatorname{erfc}(z / L)$ is the complementary error function whose tabular values are available [26]. Applying the thermal balance to the material contained in a cylindrical surface with a diameter equal to the pulse diameter, $d_{p}$, and a depth equal to $L, T_{\max }$ for a single pulse can be expressed as:

$$
T_{\max }-T_{i}=\frac{2 \epsilon W_{\max }}{\pi k d_{p}^{2}} \sqrt{\alpha t_{0}}
$$

where $\epsilon$ is the absorptivity of the radiated material (about 0.02 for grinding wheel ceramic components [1]) and $W_{\max }$ is the maximum instantaneous pulse power (12.5 MW). Substituting the proper values and assuming $T_{i}$ at room temperature $\left(20^{\circ} \mathrm{C}\right), T_{\max }$ would be about $5223^{\circ} \mathrm{C}$ for $\mathrm{CBN}$ gains and above $8226^{\circ} \mathrm{C}$ for the vitrified bond. These high temperatures will not happen in practice and the material would melt or vaporize before that. As the experiments will be done in presence of a high-pressure air nozzle, both melting and vaporization will lead to material removal. As the melting temperature of $\mathrm{CBN}$ is about $3227^{\circ} \mathrm{C}$, the pulse energy would be enough to remove both CBN grains and bond material from the wheel surface. The different maximum temperature values in grinding wheel components suggest that it is possible to selectively remove bond material without melting CBN grains. This selection of parameters would be a favorable choice for dressing applications. It can be concluded from Eq. (5) that there is a somehow linear relationship between the maximum power and maximum temperature attained in the material. According to Eq. (5), the threshold average laser power values for the removal of CBN grains, vitrified bond, and resin bond are about $19 \mathrm{~W}$, and $12 \mathrm{~W}$, and $1 \mathrm{~W}$, respectively.

As the radiation time is too short, only the heat conduction during the cooling process would be considerable. The cooling or relaxation process takes place until the radiation of the next laser pulse at $t_{1}$, which is defined by the pulse repetition rate. The temperature at the end of cooling process can be expressed as:

$$
T\left(L, t_{1}\right)=T_{\max }+\left(T_{i}-T_{\max }\right) \operatorname{erfc}\left(\frac{L}{2 \sqrt{\alpha t_{1}}}\right) .
$$

Rearranging Eq. (6), we have:

$$
\frac{T\left(L, t_{1}\right)-T_{\max }}{T_{i}-T_{\max }}=\operatorname{erfc}\left(\sqrt{\frac{t_{0}}{t_{1}}}\right) .
$$

As the ratio $t_{0} / t_{1}=4 \times 10^{-6}$ for the picosecond laser is very small, the right side of Eq. (7) approaches unity $(\operatorname{erfc}(0.002) \approx 0.998)$. In other words, the initial temperature of the next pulse would be the same as the initial body temperature. The stability of the steady laser beam in Figure 3 is also in accordance with this prediction. In fact, the diameter of the heat affected zone remains constant in time.

In addition to the pulse energy and timing, the depth of laser effects depends on the time period during which every specific zone of the grinding wheel surface is subjected to the laser beam. The longer the radiation time, the deeper the surface effects. Therefore, the depth of penetration is proportional to the laser scanning speed. Assuming the depth of laser treatment $d$ as the accumulation of the material removed per unit pulse, the following relation can be suggested in terms of laser beam scanning speed, $\nu$, and laser repetition rate, $f_{r}$ :

$$
d=\tau\left(W_{\max }\right) R L f_{r} / \nu
$$

where $\tau\left(W_{\max }\right)$ is, in general, an empirical function of pulse energy. In combination with the effective laser beam radius, $R$, measured in Figure 3 , the size and the shape of the radiated area can be approximated as a cylinder of $40 \mu \mathrm{m}$ radius whose depth is equal to $d$.

\section{Laser ablation experimental results}

As the pulse energy defines the maximum generated temperature, various power values would be used to reflect the effect of various surface temperatures, which are also different for grains and bond material. Following the predicted threshold average power values $(19 \mathrm{~W}, 12 \mathrm{~W}$, and $1 \mathrm{~W}$ for the CBN grains, vitrified bond, and resin bond materials, respectively) and the fact that the extent of heat diffusion would be controlled by the pulse repetition rate and the scanning speed, a set of experiments were conducted. The pulse repetition rate was kept constant at $400 \mathrm{kHz}$ for all the tests. A set of average laser power values and two sets of scanning speed values were chosen for the experiments. Table 2 presents the chosen sets of parameters.

An air nozzle was used to take the debris and the molten material away from the radiation zone. In 
Table 2. The parameters assigned for laser conditioning experiments.

\begin{tabular}{cc}
\hline Parameter & Values \\
\hline Average laser power $(\mathrm{W})$ & $2,10,15,20,25,50$ \\
Scanning speed for vitrified bond CBN wheel $(\mathrm{mm} / \mathrm{s})$ & $5,10,20,40$ \\
Scanning speed for resin bond CBN wheel $(\mathrm{mm} / \mathrm{s})$ & $100,150,200$ \\
\hline
\end{tabular}

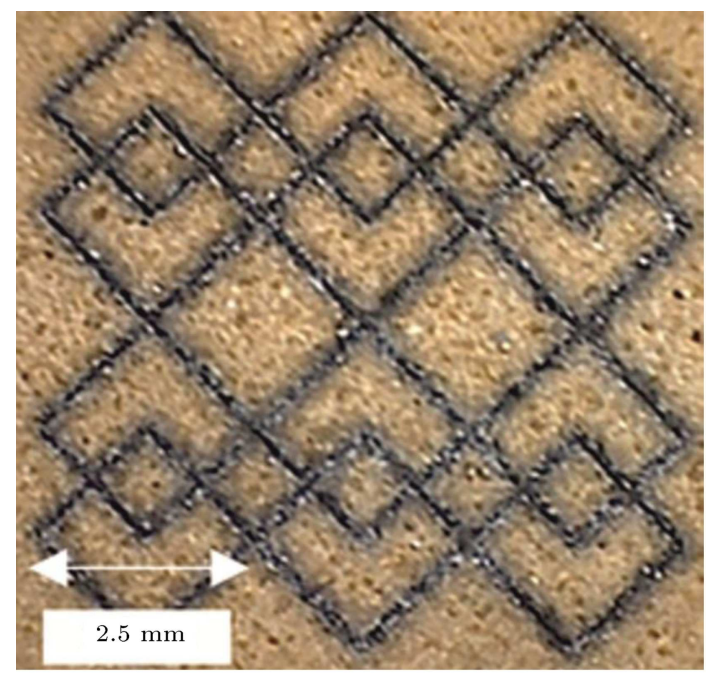

Figure 4. The generated pattern for the laser conditioning tests.

order to have constant cooling and wiping effect, the pressure ( 7 bar), distance, and orientation of the nozzle were kept constant. The pattern shown in Figure 4 is generated on the grinding wheel surface for further surface investigations and measurements.

In order to investigate the ablation of the grinding wheel components qualitatively, a more profound study of the radiated surfaces would be needed. Accordingly, SEM images of the vitrified and resin bond samples are taken. The laser treatment of resin bond CBN grinding wheel with $2 \mathrm{~W}$ average laser power and $150 \mathrm{~mm} / \mathrm{s}$ scanning speed is shown in Figures 5 and 6 presents the trace generated with $15 \mathrm{~W}$ average laser power (37.5 $\mu \mathrm{J}$ single pulse energy) and $10 \mathrm{~mm} / \mathrm{s}$ scanning speed on vitrified bond $\mathrm{CBN}$ grinding wheel. As it can be seen, the bond material is slightly molten in both cases, while the cutting grains remain unchanged. Some cavities can be seen, which can be due to the removal of some parts of the bond material with the air stream. Therefore, $2 \mathrm{~W}$ and $15 \mathrm{~W}$ are the threshold laser power values suggested by the experiments for the removal of resin and vitrified bond, respectively. The experimentally achieved threshold values agree qualitatively with the predictions of the thermal analysis, but the individual values are larger in the experiments. This deviation can be associated with the energy loss of the laser beam through the optical equipment and the blockage of the laser beam just before incidence on the wheel surface by the ablated debris.

By increasing the laser power, the treatment of

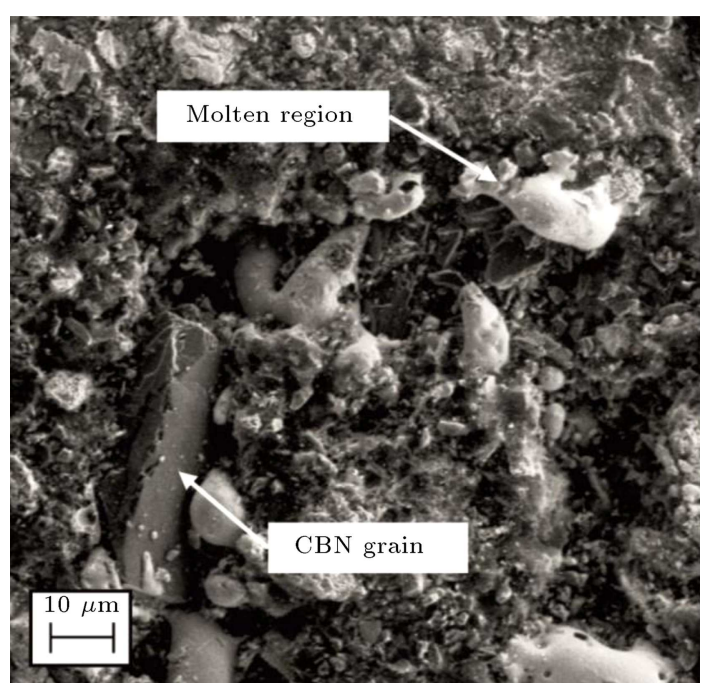

Figure 5. SEM image of laser treatment on resin bond CBN wheel with $2 \mathrm{~W}$ average laser power $(5 \mu \mathrm{J}$ single pulse energy) and $150 \mathrm{~mm} / \mathrm{s}$ scanning speed.

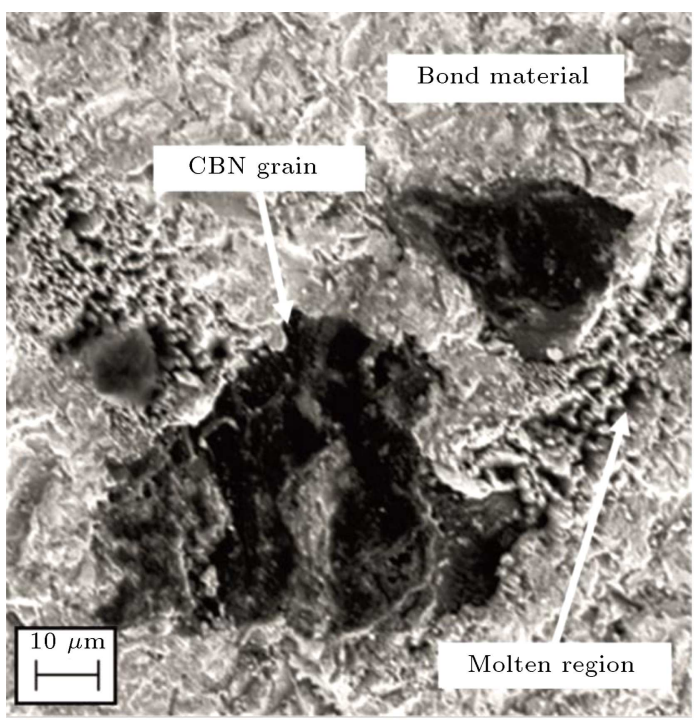

Figure 6. SEM image of laser treatment on vitrified bond CBN wheel with $15 \mathrm{~W}$ average laser power $(37.5 \mu \mathrm{J}$ single pulse energy) and $10 \mathrm{~mm} / \mathrm{s}$ scanning speed.

the bond material becomes more significant. Up to $20 \mathrm{~W}$ average laser power (50 $\mu \mathrm{J}$ pulse energy), the bond material in both resin and vitrified CBN grinding wheels can be removed effectively while the CBN grains are not still ablated. Figures 7 and 8 present the traces of laser treatment on resin bond and vitrified bond CBN wheels with $20 \mathrm{~W}$ average laser power, and 


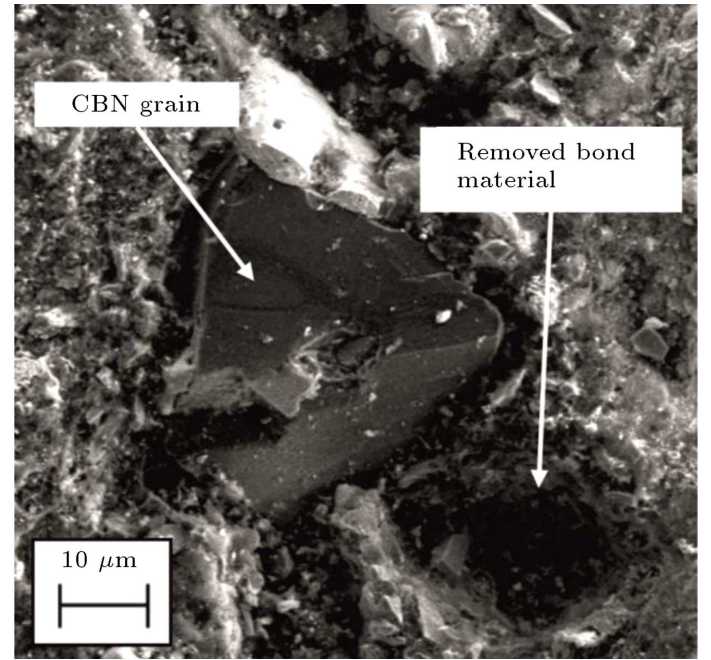

Figure 7. SEM image of laser treatment on resin bond CBN wheel with $20 \mathrm{~W}$ average laser power $(50 \mu \mathrm{J}$ single pulse energy) and $150 \mathrm{~mm} / \mathrm{s}$ scanning speed.

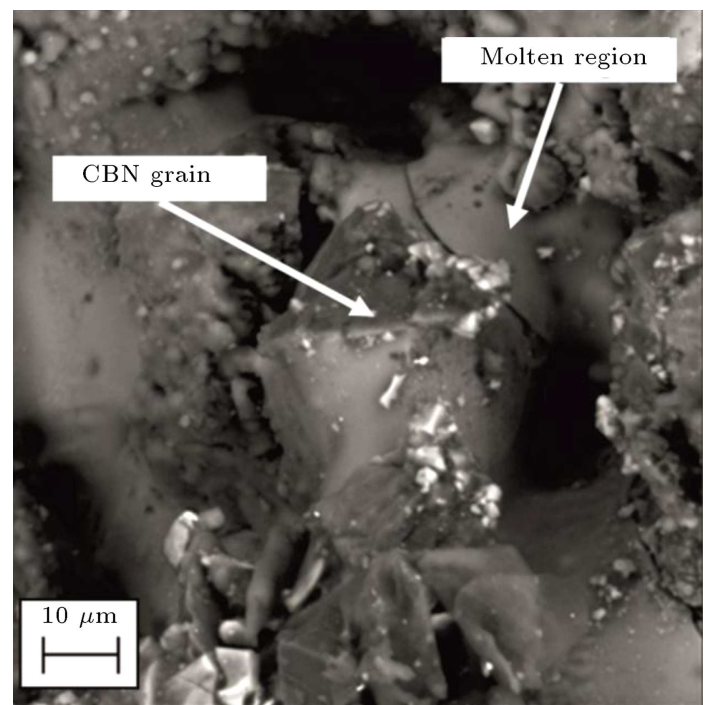

Figure 8. SEM image of laser treatment on vitrified bond CBN wheel with $20 \mathrm{~W}$ average laser power $(50 \mu \mathrm{J}$ single pulse energy) and $10 \mathrm{~mm} / \mathrm{s}$ scanning speed.

$150 \mathrm{~mm} / \mathrm{s}$ and $10 \mathrm{~mm} / \mathrm{s}$ scanning speeds, respectively. Some cracks can be detected on the surface of the solidified bond connections, which could be caused by the sudden cooling of the bond material.

The removal of the CBN grains starts with average laser power values of about $25 \mathrm{~W}$ corresponding to $62.5 \mu \mathrm{J}$ single pulse energy. Therefore, this value represents the threshold laser power value for the treatment of CBN grains. A laser trace generated with $25 \mathrm{~W}$ laser power and $10 \mathrm{~mm} / \mathrm{s}$ scanning speed on vitrified bond $\mathrm{CBN}$ wheel is presented in Figue 9. Using higher laser powers, the cutting grains and the bond material will be effectively ablated. Figure 10 presents a trace generated with $50 \mathrm{~W}$ average laser

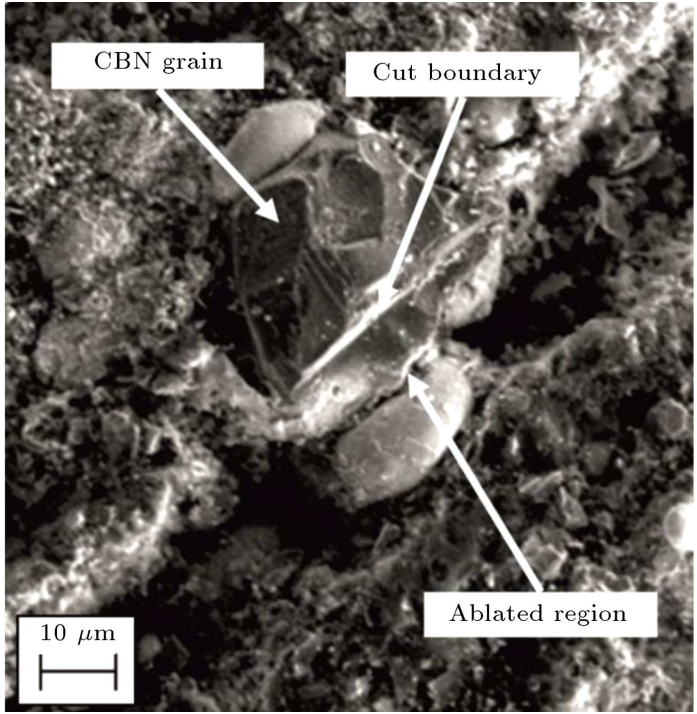

Figure 9. SEM image of laser treatment on vitrified bond CBN wheel with $25 \mathrm{~W}$ average laser power $(62.5 \mu \mathrm{J}$ single pulse energy) and $10 \mathrm{~mm} / \mathrm{s}$ scanning speed.

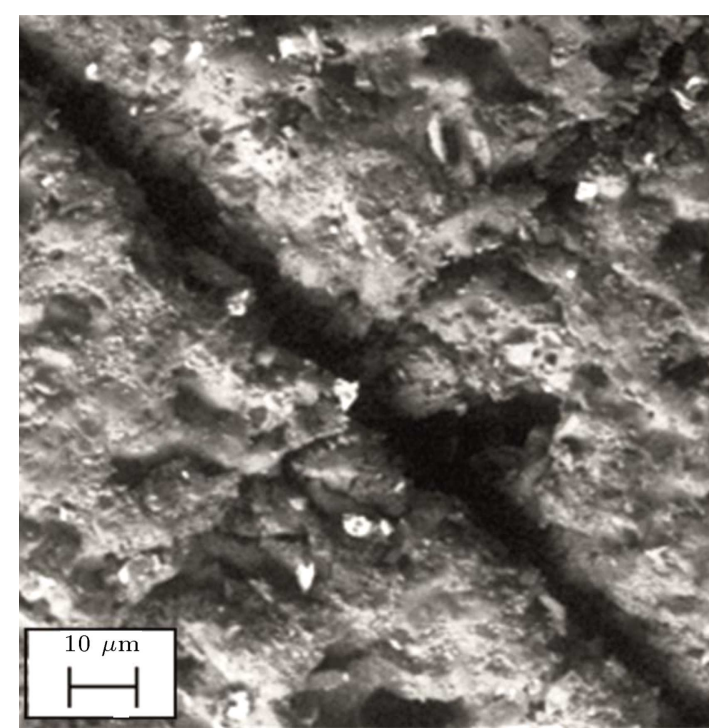

Figure 10. SEM image of laser treatment on vitrified bond CBN wheel with $50 \mathrm{~W}$ average laser power $(125 \mu \mathrm{J}$ single pulse energy) and $10 \mathrm{~mm} / \mathrm{s}$ scanning speed.

power and $10 \mathrm{~mm} / \mathrm{s}$ scanning speed on vitrified bond $\mathrm{CBN}$ wheel, where a continuous groove is generated on the grinding wheel surface.

In order to survey the geometry of the grooves generated by laser, confocal microscopy of the surfaces was performed using a nanofocus surf microscope. Figure 11(a) and (b) present confocal images of two grooves generated on the vitrified bond CBN wheel with $10 \mathrm{~mm} / \mathrm{s}$ scanning speed, and $20 \mathrm{~W}$ and $50 \mathrm{~W}$ average laser powers, respectively. The corresponding cross section profiles ("A-A" and "B-B") are shown in Figure $12(\mathrm{a})$ and (b).

The approximate depths are shown with vertical 


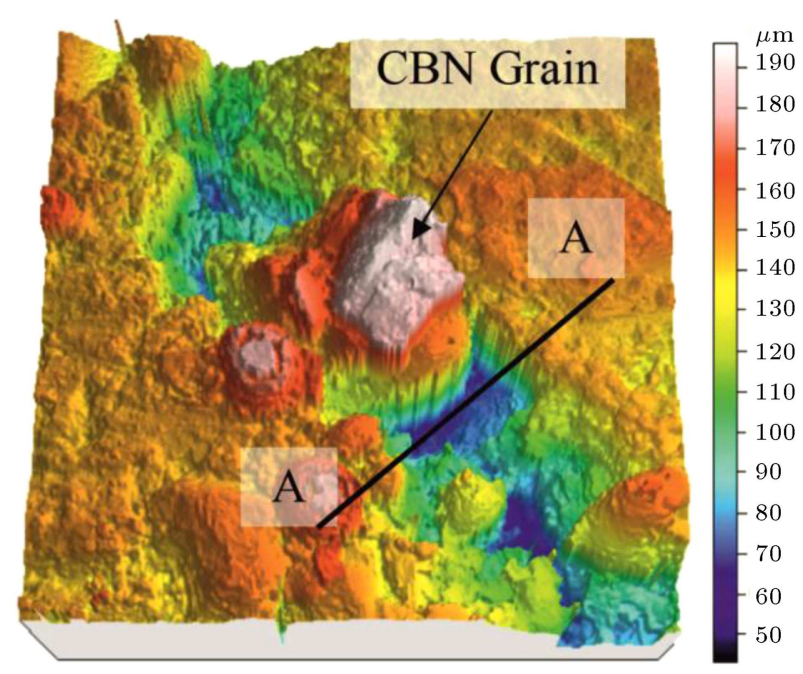

(a)

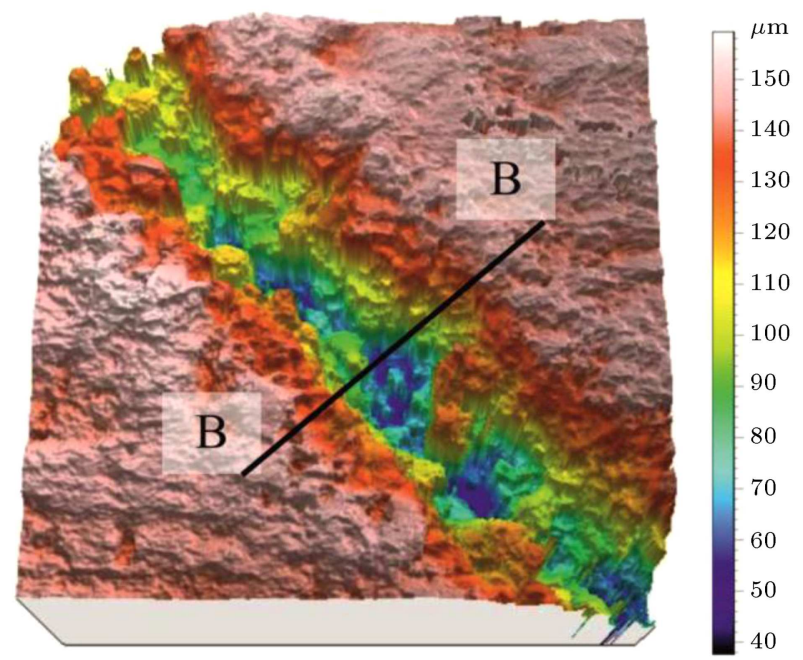

(b)

Figure 11. Confocal image of laser treatment on vitrified bond CBN wheel with $10 \mathrm{~mm} / \mathrm{s}$ scanning speed: (a) $20 \mathrm{~W}$ average laser power, and (b) $50 \mathrm{~W}$ average laser power.

arrows in Figure 12. As the average laser power for generating the groove in Figure 11 is lower than the threshold power value for the ablation of CBN grains and higher than the threshold value for the ablation of the bond material, the CBN grain shown in the figure has not been treated while the bond material is scratched. The depths of the grooves presented in Figure 11(a) and (b) are approximately $80 \mu \mathrm{m}$ and $90 \mu \mathrm{m}$, respectively. By increasing the average laser power up to more than two times (from $20 \mathrm{~W}$ in Figure 11(a) to $50 \mathrm{~W}$ in Figure 11(b)), the depth of the grooves in the bond material increases by only a few percent. In other words, the depth of laser treatment is nearly independent of the laser power and the function $\tau$ in Eq. (6) is not a strong function of pulse energy. In order to generated grooves of the same depth in the resin bond grinding wheel, much higher scanning speeds would be needed, which is in

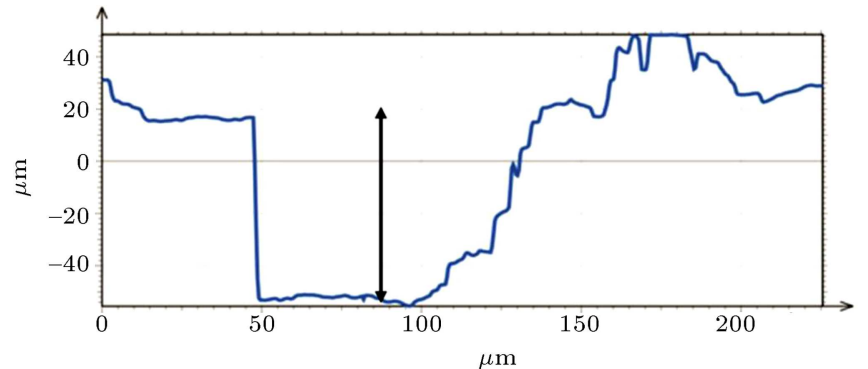

(a)

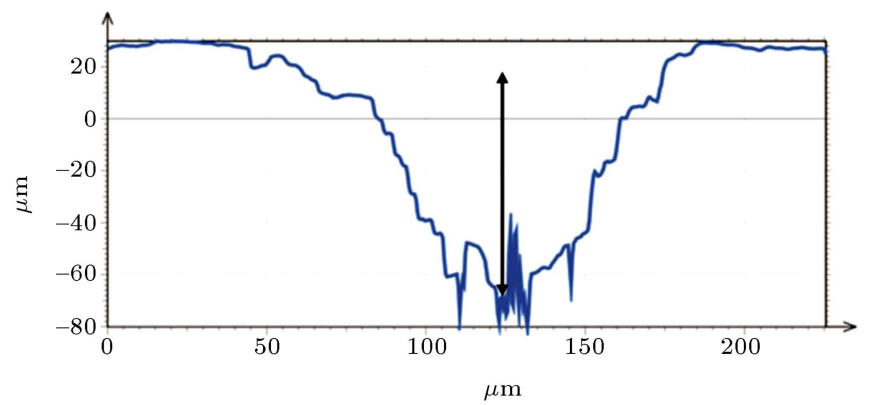

(b)

Figure 12. Cross section profiles of the laser grooves in Figure 11: (a) Cross: section "A-A", and (b) cross section "B-B".

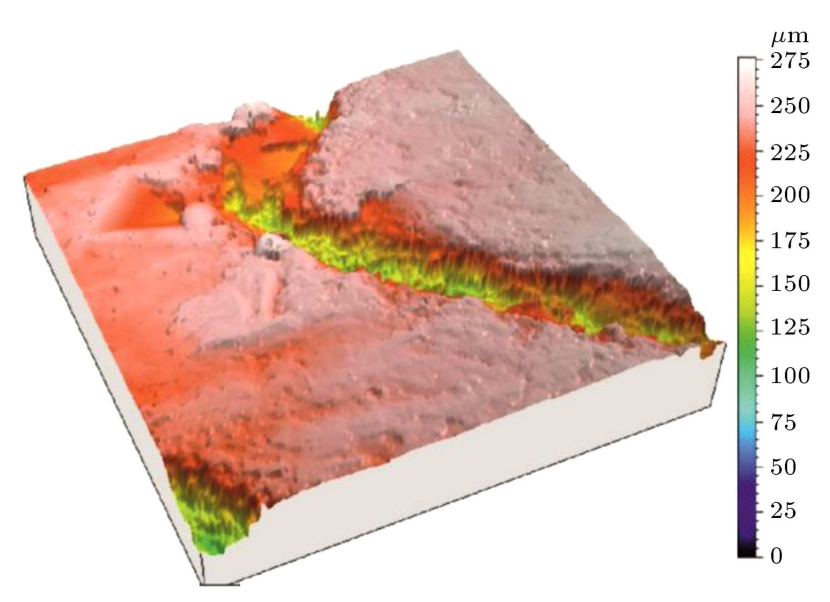

Figure 13. Confocal image of laser treatment on resin bond CBN wheel with $200 \mathrm{~mm} / \mathrm{s}$ scanning speed and $50 \mathrm{~W}$ average laser power.

agreement with the statement that the depth of grooves generated with a pulsed laser depends mostly on the scanning speed. Figure 13 presents the confocal image of a groove generated with $50 \mathrm{~W}$ average laser power and $200 \mathrm{~mm} / \mathrm{s}$ scanning speed on the resin bond CBN wheel surface. The corresponding cross section profile is shown in Figure 14, where the depth of groove can be about $100 \mu \mathrm{m}$.

Figure 15 illustrates a complete resin bond grinding wheel, which was structured with $50 \mathrm{~W}$ average laser power and $200 \mathrm{~mm} / \mathrm{s}$ scanning speed. The grinding wheel will be utilized and assessed in grinding process in the further steps of the research. 


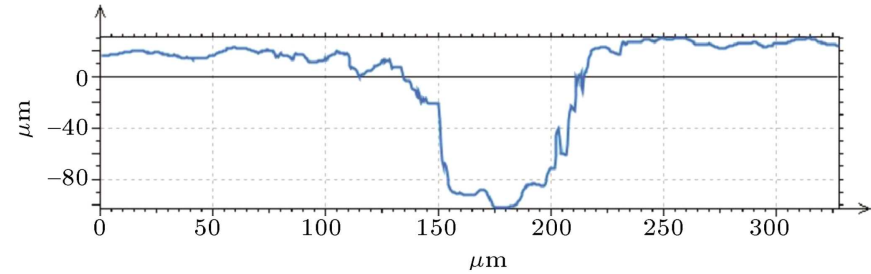

Figure 14. Cross section profile of the laser groove in Figure 13.

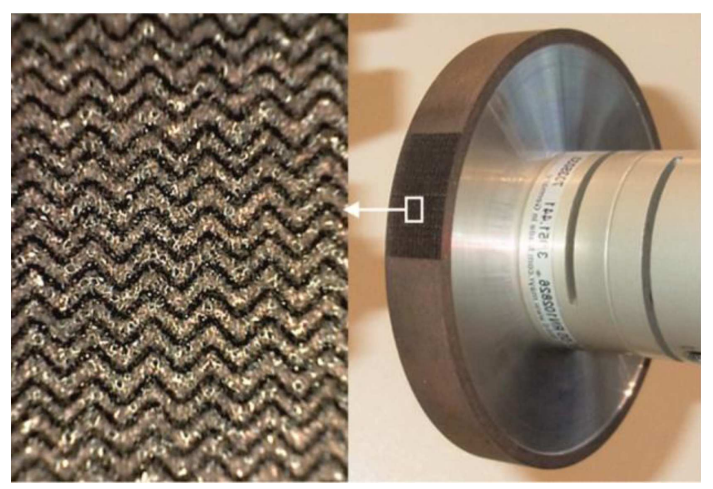

Figure 15. Resin bond CBN wheel structured with $50 \mathrm{~W}$ average laser power and $200 \mathrm{~mm} / \mathrm{s}$ scanning speed.

Table 3. The threshold laser power values for the ablation of grinding wheel components.

\begin{tabular}{lcc}
\hline $\begin{array}{c}\text { Average } \\
\text { laser power }\end{array}$ & Thermal model & Experiment \\
\hline CBN grains & $19 \mathrm{~W}$ & 25 \\
Vitrified bond & $12 \mathrm{~W}$ & 15 \\
Resin bond & $<1 \mathrm{~W}$ & 2 \\
\hline
\end{tabular}

The conducted analytical approach provides a correlation between the laser radiation parameters and the characteristics of the treated grinding wheel surface. The extent of cutting grain and bond material treatment is controlled by suitable values of laser power and scanning speed. The experimental results are in accordance with the analytical model. The threshold average laser power values for treatment of grinding wheel components are summarized in Table 3 .

The laser power values predicted by the thermal modeling are slightly smaller than the experimental results. This discrepancy could be duo to the energy loss of the laser beam through the optical components.

\section{Conclusion}

A picosecond laser device was integrated with a cylindrical grinding machine to perform in-place laser treatment of CBN grinding wheels. The present research can be summarized in the following points:

- It is suggested analytically and verified experimen- tally that besides the thermal properties of the material, the maximum surface temperature depends directly on the laser pulse power;

- The critical average laser power values for the removal of the $\mathrm{CBN}$ grains, vitrified bond, and metal bond are found to be about $25 \mathrm{~W}, 15 \mathrm{~W}$, and $2 \mathrm{~W}$, respectively, which correspond to $62.5 \mu \mathrm{J}, 37.25 \mu \mathrm{J}$, and $5 \mu \mathrm{J}$ pulse energy values, respectively. The energy gap between the threshold values corresponds to the laser power range in which bond material can be removed while the grains remain undamaged on the grinding wheel surface;

- The depth of thermal process penetration depends mostly on the laser scanning speed. The lower the scanning speed, the more time available for deeper temperature diffusion;

- It is possible to perform a wide range of conditioning processes (truing, dressing and structuring) of the resin and vitrified bond CBN grinding wheels with pulsed lasers when the parameters are chosen properly.

\section{Nomenclature}

$c$

$d \quad$ Depth of laser treatment (thermal field penetration) $(\mathrm{m})$

$d_{p} \quad$ Effective pulsed zone diameter $(\mathrm{m})$

erfc Complementary error function

$f_{r} \quad$ Laser pulse repetition rate $(\mathrm{Hz})$

$k$

Thermal conductivity $\left(\mathrm{W} / \mathrm{m}^{\circ} \mathrm{C}\right)$

Thermal diffusion length

$q^{\prime \prime} \quad$ Heat generation per unit volume $\left(\mathrm{W} / \mathrm{m}^{3}\right)$

$R \quad$ Effective laser beam radius $(\mathrm{m})$

$T \quad$ Temperature $\left({ }^{\circ} \mathrm{C}\right)$

$T_{i} \quad$ Initial temperature of material $\left({ }^{\circ} \mathrm{C}\right)$

$T_{\max } \quad$ Maximum surface temperature $\left({ }^{\circ} \mathrm{C}\right)$

$t \quad$ Time $(\mathrm{s})$

$t_{0} \quad$ Laser pulse width (s)

$t_{1} \quad$ Laser pulse relaxation time $(\mathrm{s})$

$\nu \quad$ Laser scanning speed $(\mathrm{m} / \mathrm{s})$

$W_{\max } \quad$ Maximum single-pulse power (W)

$z \quad$ Spatial coordinate in the depth direction $(\mathrm{m})$

Thermal diffusivity $\left(\mathrm{m}^{2} / \mathrm{s}\right)$

Thermal absorption

$\nabla \quad$ Del operator

$\rho \quad$ Density $\left(\mathrm{kg} / \mathrm{m}^{3}\right)$

$\tau \quad$ Groove depth empirical coefficient (-) 


\section{References}

1. Marinescu, I.D., Hitchinger, M., Uhlmann, E., Rowe, W.B. and Inasaki I., Handbook of Machining with Grinding Wheels, CRC Press (2007).

2. Syoji, K. "Truing and dressing of superabrasive wheels", J. of Mach. Tools, 2, pp. 18-26 (1989).

3. Babu, N.R. and Radhakrishnan, V. "Investigations on laser dressing of grinding wheels 2014 Part I: preliminary study" J. of Engineering for Industry, 111, pp. 244-252 (1989).

4. Babu, N.R. and Radhakrishnan, V. "Investigations on laser dressing of grinding wheels 2014. Part II: Grinding performance of a laser dressed aluminum oxide wheel", J. of Engineering for Industry, 111, pp. 253-261 (1989).

5. Dahotre, N.B. and Harimkar S.P., Laser Fabrication and Machining of Materials, Springer, Ney York (2008).

6. Babu, N.R. and Radhakrishnan, V. "Influence of dressing feed on the performance of laser dressed $\mathrm{Al}_{2} \mathrm{O}_{3}$ wheel in wet grinding", Int. J. of Mach. Tools and Manufact., 35(5), pp. 661-671 (1995).

7. Zhang, C. and Jing, Y.C. "A novel laser-assisted truing and dressing technique for vitrified CBN wheels", Int. J. of Mach. Tools and Manufact., 42, pp. 825-835 (2002).

8. Zhang, C. and Jing, Y.C. "Wear of diamond dresser in laser assisted truing and dressing of vitrified $C B N$ wheels", Int. J. Mach. Tools and Manufact., 43, pp. 41-49 (2003).

9. Tian, Y. and Shin, Y.C. "Thermal modelling and experimental evaluation of laser-assisted dressing of superabrasive grinding wheels", Proc. of Ins. of Mech. Eng., 221, pp. 605-616 (2007).

10. Hoffmeister, H.W. and Timmer, J.H. "Laser conditioning of superabrasive grinding wheels", Industrial Diamond Review, 60(7), pp. 209-218 (2000).

11. Xi, X.Z., Chen, G.Y. and Li, L.J. "Dressing of resinbonded superabrasive grinding wheels by means of acousto-optic Q-switched pulsed Nd:YAG laser", Opt. and Laser Tech., 36, pp. 409-419 (2004).

12. Hosokawa, A., Ueda, T. and Yunoki, T. "Laser dressing of metal bonded diamond wheel", CIRP Annals, 55(1), pp. 329-332 (2006).

13. Khanger, A., Kenik, E.A. and Dahotre, N.B. "Microstructure and microtexture in laser-dressed alumina grinding wheel material", Ceramic Int., 31(4), pp. 621629 (2005).

14. Khangar, A., Dahotre, N.B., Jackson, M.J. and Robinson, G.M. "Laser dressing of alumina grinding wheels", J. of Mat. Eng. Perf., 15(2), pp. 178-181 (2006).

15. Dold, C., Transchel, R., Rabiey, M., et al. "A study on laser touch dressing of electroplated diamond wheels using pulsed picosecond laser sources", CIRP AnnalsMan. Tech., 60, pp. 363-366 (2011).
16. Rabiey, M., Dold, C., Transchel, R. and Wegener, K. "Influence of picosecond laser touch dressing of electroplated diamond wheels on the dressing of sic vitrified bond wheel", Adv. Mat. Res., 325, pp. 189194 (2011).

17. Zahedi, A., Azarhoushang, B. and Akbari, J. "Optimization and application of laser-dressed $\mathrm{cBN}$ grinding wheels", Advanced Materials Research, 1136, pp. 9096 (2016).

18. Walter, C., Komischke, T., Weingürtner, E., Wegener, K. "Structuring of CBN grinding tools by ultrashort pulse laser ablation", Procedia CIRP, 14, pp. 31-36 (2014).

19. Malkin, S., Grinding Technology: Theory and Applications of Machining with Abrasives, 2nd Edn, Industrial Press, New York (2008).

20. Younis, M.A. and Alawi, H. "Probabilistic analysis of the surface grinding process", Trans. Of Can. Soc. Mech. Eng., 8(4), pp. 208-213 (1984).

21. Azarhoushang, B. "Intermittent Grinding of Ceramic Matrix Composites", PhD Dissertation, Institut for Fertigungstechnologie Keramischer Bauteile (IFKB) der Universitat Stuttgart, Stuttgart (2011).

22. Incropera, F.P., and DeWitt, D.P., Introduction to Heat Transfer, 6th Edn., John Wiley \& Sons Incorporated, New York (2011).

23. Wang, X.Y., Wu, Y.B., Wang, J., Xu, W.J. and Kato, M. "Absorbed energy in laser truing of a small vitrified CBN grinding wheel", J. of Mat. Proc. Tech., 164165, pp. 1128-1133 (2005).

24. Beyler, C.L. and Hirschler, M.M. "Thermal decomposition of polymers" In: SFPE Handbook of Fire Protection Engineering, 3rd Edn., NFPA, Quincy, MA (2001).

25. Matthias, E., Reichling, M., Siegel, J., Kading, O.W., Petzoldt, S., Skurk, H., Bizenberger, P. and Neske, E. "The influence of thermal diffusion on laser ablation of metal films", Applied Physics A, 58(2), pp. 129-136 (1994).

26. Thirumaleshwar, M., Fundamentals of Heat and Mass Transfer, 1st Edn., Pearson, Dorling Kindersley (2006).

\section{Biographies}

Ali Zahedi was born in 1984. He obtained his BSc degree in Fluid Mechanics and Heat Transfer from Shiraz University in 2006 and his MSc and PhD degrees in Applied Mechanics from Sharif University of Technology in 2009 and 2015, respectively. He is working in Institute for Precision Machining, Furtwangen University, Germany, as a Research Associate.

Bahman Azarhoushang graduated from Sharif University of Technology, Iran, in 2006. He received his $\mathrm{PhD}$ in Mechanical Engineering from Stuttgart University, Germany, in 2011. He was head of the research 
and development department of Baerhausen Company before joining the Furtwangen University in 2013. He has been a member of Mechanical and Biomedical Engineering Faculty of Furtwangen University since September 2013 and, simultaneously, the Director of the Institute of Grinding and Precision Technology (KSF). Professor Azarhoushang has published more than 50 papers in different languages. Numerous lectures at national and international conferences proof his research activities. He is editor of the journal of "Mechanical Sciences (MS)" and works as a reviewer of international journals "Machine Tools and Manufacture" (Elsevier) and "Advanced Manufacturing Technology" (Springer).Currently, he works on various German national, DFG, AIF, and BMFT projects.
Javad Akbari received his BSc degree from the School of Mechanical Engineering at Sharif University of Technology, Tehran, Iran, in 1985; MSc degree from Utsunomiya University, Utsunomiya, Japan, in 1990; his PhD from Chiba University, Chiba, Japan, in 1993. During 1993-95, he was a CNC machine tool designer in Seiko Seiki, Seiko Instruments Inc. He joined Sharif University of Technology in 1995 and spent five years as an Assistant Professor in the School of Mechanical Engineering. Then, he became an Associate Professor in Tokyo Institute of Technology in 2000. He returned to Sharif University of Technology in 2003 in his previous position. Dr. Akbari is currently a Professor in the School of Mechanical Engineering at Sharif University of Technology. 